\title{
ESTRATEGIA DE SEGURIDAD NACIONAL Y EL LIBRO BLANCO DE LA DEFENSA DE LA REPÚBLICA DE ARGENTINA ${ }^{1}$
}

\author{
Oscar Felipe Barrera Herrera \\ Sergio Enrique Rodríguez Salcedo \\ María Angélica Ramos Ortega \\ Luis Fernando Fonseca Naranjo
}

\section{Introducción}

Los gobiernos autoritarios de Argentina, marcados por violaciones a los derechos humanos fruto de acciones violentas - como genocidios, desapariciones forzadas, torturas, apropiación indebida de bienes, exilios, corrupción y descalabro económico-, permearon la dinámica política e impactaron en el tejido social de la población.

La permanente intervención política que las Fuerzas Armadas protagonizaron durante largos períodos desde 1930, sobre todo los golpes cívico-militares, que constituyen la más radical y profunda de sus múltiples formas, tuvo un fuerte impacto sobre el diseño de la política de Defensa, su sistema y el Instrumento Militar. Además de transformar a las relaciones civiles-militares como un problema para su definición, condicionó a través de los intereses corporativos de las Fuerzas las prioridades y los fundamentos de la ideología del partido militar. (Juncal, 2013, p. 33)

En la década de los cincuenta se manifiesta una visión que intentaba definir la relación de las Fuerzas Armadas dentro del contexto la Guerra Fría. De este modo, el posible conflicto limítrofe con Brasil y Chile permeó la visión estratégica de la defensa y la seguridad en Argentina, así mismo lo hizo el llamado "enemigo interno", entendido como el comunismo y todo aquello que estuviera relacio-

1 Este capítulo del libro hace parte del proyecto de investigación de la Maestría en Seguridad y Defensa Nacionales, titulado "Desafíos y Nuevos Escenarios de la Seguridad Multidimensional en el Contexto Nacional, Regional y Hemisférico en el Decenio 2015-2025”, el cual hace parte del Grupo de Investigación Centro de Gravedad de la Escuela Superior de Guerra "General Rafael Reyes Prieto", reconocido y categorizado en (A) por Colciencias, con el código COL0104976. 
nado con partidos o movimientos de izquierda, que repercutiría además en toda Latinoamérica.

En este contexto - cuando tanto en el plano nacional como en el internacional predominaban las amenazas; presiones; desestabilizaciones políticas, sociales y económicas; e inclusive los conflictos bélicos convencionales o de baja intensidad, promovidos por las superpotencias — Estados Unidos concibe y promueve la doctrina de seguridad nacional para el hemisferio occidental, que se convierte en base y sustento para la creación y desarrollo de regímenes autoritarios que afectaron en la década de los sesenta y setenta a varios países del Cono Sur y de Centroamérica.

En Argentina, la doctrina de seguridad nacional fue aplicada a través de la Ley n. ${ }^{\circ} 16.970$ de 1966, que justificó la represión interna por parte del instrumento militar y las fuerzas de seguridad y promovió una perversa cooperación regional con el resto de las dictaduras suramericanas para mejorar la operatividad represiva en su conjunto. Así, los gobiernos de facto mantenían vigentes las "hipótesis de conflicto" con sus vecinos, que aunaban sus esfuerzos en la represión del "enemigo interno", como se evidencia históricamente en la última dictadura militar de 1976 a 1983 (Juncal, 2013, p. 34).

Uno de los hechos que develan el declive de la implementación de la doctrina de seguridad para el caso de Argentina fue la derrota en la Guerra de las Malvinas (1982), pues demostró fallas de importante envergadura para las Fuerzas Armadas, como fueron, entre otras, la ausencia de cooperación entre las tres fuerzas, una previsión estratégica desacertada basada en hipótesis de conflicto erradas para la época, además de una ejecución poco sistemática.

\section{Contexto de políticas}

Al finalizar las dictaduras militares y llegar la democracia a la Argentina con la elección del presidente Raúl Alfonsín (1983-1988), el Gobierno enfrentó el desafío de reinstitucionalizar a las Fuerzas Armadas dentro de un proceso político y democrático relacionado con la subordinación del poder militar al civil. En este contexto, dicho control se constituyó en una condición indispensable para la gobernabilidad democrática, que dependía de dos condiciones específicas, por un lado, del ejercicio efectivo del Gobierno sobre las Fuerzas Militares y, por otro, de la subordinación castrense a las autoridades civiles gubernamentales. Sin embargo, para tales efectos fue necesario desarticular los márgenes de autonomía alcanzados por las instituciones castrenses durante la dictadura, así como eliminar las prerrogativas políticas con las que aún contaban. 
Lo anterior determinó la redefinición del rol institucional de las Fuerzas Armadas, de sus misiones y tareas específicas y, en particular: la desmilitarización de la seguridad interior; el diseño e implementación de una profunda reforma de las estructuras orgánico-funcionales y doctrinales de las instituciones militares, con el fin de eliminar las profundas deformaciones que poseían; así como la revisión de las violaciones a los derechos humanos cometidas bajo el régimen militar, demanda ésta que se sustentaba sobre un amplio consenso social (Saín, 2002, p. 3).

Bajo el gobierno 'alfonsista' se establecen nuevos lineamientos legislativos que crean un nuevo horizonte en materia de seguridad y defensa nacionales, también se estipula la Ley de Defensa Nacional N. ${ }^{\circ} 23.554$, promulgada el 13 de abril de 1988, que establece "las bases jurídicas, orgánicas y funcionales fundamentales para la preparación, ejecución y control de la defensa nacional” (art. 1); así mismo, define la defensa nacional, cómo se debe enfrentar al enemigo y su finalidad (art. 2); separa a la defensa nacional de la seguridad interior y señala que esta última será protegida por una ley (art. 4); además, plantea la estructura del sistema de defensa, la organización de las Fuerzas Armadas, el servicio de defensa nacional, la organización territorial y la movilización, entre otras disposiciones generales.

En este orden de ideas, se puede concluir que bajo la gestión del presidente Alfonsín se avanzó de manera positiva en la subordinación del poder militar al civil, aunque durante el proceso se presentarán permanentes conflictos y pujas entre el Gobierno y los militares, ya que la política como tal se centró en la revisión judicial de las violaciones a los derechos humanos. No obstante, como lo señala Saín (2002), al final de su mandato quedaron sin solucionar dos cuestiones altamente conflictivas como lo fueron:

El persistente reclamo castrense de una "solución política" a la revisión judicial del pasado, esto es, la demanda de alguna medida gubernamental, amnistía, conmutación de penas y/o indulto que beneficiara a los pocos uniformados que aún estaban procesados judicialmente y a los ex comandantes de la última dictadura que a fines de 1985 habían sido condenados a prisión por la comisión de numerosos delitos graves cometidos durante el periodo autoritario. El desprocesamiento de más de 1150 militares también acusados de la comisión de esos delitos a través de las leyes de Punto Final — diciembre de 1986 — y de Obediencia Debida — julio de 1987no había conseguido desactivar el conflicto abierto en este rubro. (p. 3)

Posteriormente, bajo la presidencia de Carlos Menem (1989-1999) y en un contexto determinado por de inconformidad de algunas facciones castrenses — que venía desde el gobierno de Alfonsín—, se realizan dos grandes amnistías (octubre de 1989 y diciembre de 1990) a favor de algunos militares, policías y civiles que 
estaban enfrentando condenas y procesos relacionados con la represión política de los años 1976 y 1983 (Saín, 2002, p. 3).

Lo anterior significó el cierre de una serie de conflictos que tuvieron gran importancia política en el mandato alfonsista. Cuando concluye esta etapa, la política militar desarrollada por el gobierno de Menen se centró en la adecuación de las prioridades en materia de política exterior, con especial énfasis en la tradicional posición de confrontación con los Estados Unidos y el fortalecimiento de las relaciones bilaterales con dicho país. Así mismo, en este periodo se decidió impedir todo tipo de iniciativa que implicara escenarios de confrontación con gran Bretańa, esto, por el litigio existente sobre la soberanía de las Islas Malvinas (Gil, 5 de julio de 1999).

En este orden de ideas, el objetivo de la diplomacia argentina fue la de aunar esfuerzos para lograr un acercamiento con Gran Bretaña, lo que tuvo como consecuencia el restablecimiento de las relaciones diplomáticas bilaterales y el levantamiento de la zona de exclusión entorno a las Malvinas establecida por el Gobierno británico.

Por otra parte, en materia de política interna, el gobierno de Menen promulga la Ley de Seguridad Interior N. o 24.059, del 6 de enero de 1992, en la que señala con mayor precisión la diferencia entre seguridad y defensa y define la seguridad interior como:

la situación de hecho basada en el derecho en la cual se encuentran resguardadas la libertad, la vida y el patrimonio de los habitantes, sus derechos y garantías y la plena vigencia de las instituciones del sistema representativo, republicano y federal que establece la Constitución Nacional. (art. 2)

Además, establece que la seguridad interior tiene como ámbito espacial el territorio de Argentina, sus aguas jurisdiccionales y su espacio aéreo. Por otra parte, crea el Consejo de Seguridad, que tiene la misión de asesorar al ministro del Interior en la elaboración de las políticas correspondientes al ámbito de la seguridad interna, así como en los planes y la ejecución de las acciones dirigidas a garantizar un adecuado nivel de seguridad interior, entre otros asuntos (Ley 24.059).

Las leyes mencionadas son consideradas la base sobre la cual se elaboró la reestructuración de la Defensa Nacional y de las Fuerzas Armadas, que se concreta con la promulgación de la Ley N. ${ }^{\circ} 24.948$, del 3 de abril de 1988, que establece las bases políticas, orgánicas y funcionales fundamentales para dicha reestructuración (art. 1). El objetivo fundamental de esa ley es forjar los cimientos para la modernización del instrumento militar, aclarar la estructura interna de este teniendo en cuenta el 
despliegue territorial, la modernización de su equipamiento, la formación de sus efectivos y el alistamiento, adiestramiento y sostenimiento de sus medios, todo ello, acorde con la forma de la conducción política y civil de la defensa nacional.

Por otra parte, la organización definitiva de la defensa nacional fue establecida por el Decreto N. 727 del 12 de junio de 2006, bajo el gobierno de Néstor Kirchner, a través del cual se reglamenta la Ley de Defensa Nacional y se pone en marcha el proceso de reconversión definitivo de las Fuerzas Armadas, lo que asegura su conducción civil y política.

En términos generales, los años subsiguientes estuvieron marcados por la necesidad del perfeccionamiento del marco normativo y doctrinario, así como de las directivas y normas que representarán la actualidad argentina, en este sentido, se consolidó una estructura jurídica planteada ya en las disposiciones del Decreto N. ${ }^{\circ}$ 1729 de 2007, que reglamentaba el Ciclo de Planeamiento de la Defensa Nacional (Ugarte, 2017). Posteriormente, se aprueba la Directiva de Política de Defensa Nacional bajo el Decreto N.o 1714 de 2009, que inició la primera aplicación del ciclo antes referido y puso de manifiesto la necesidad de continuar con el proceso de definición de las políticas educativas, las estructuras de educación, la formación y la actualización de las Fuerzas Armadas, a través de las Escuela de Defensa Nacional.

Fue reiterado que el Planeamiento Estratégico Militar y el diseño de fuerzas que del mismo se derivara y se elaboraría conforme al criterio de "capacidades", destacándose también la necesidad de reducir estructuras administrativas, así como la vigencia del principio de "concentración-dispersión" para optimizar los recursos y el esfuerzo logístico, la concentración de unidades y la unificación de todas aquellas funciones, actividades y/o servicios de naturaleza no específica. (Ugarte, 2017, p. 260)

Luego, surge una nueva Directiva de Política de Defensa Nacional, aprobada por el Decreto N. 2645 de 2014, que considera a la Antártida como un territorio de importantes recursos naturales, con un estatus internacional especial. Además, el decreto pone de manifiesto las novedades tecnológicas en materia de defensa, entre las que se destacó la dimensión ciberespacial, así como la necesidad de recurrir a la infraestructura y logística militares para la gestión y prevención de catástrofes naturales o situaciones de emergencia.

Así mismo, este decreto ratificó el carácter defensivo en términos del diseño de las Fuerzas y de sus capacidades, lo que se traduce en una bidimensionalidad, es decir, la dimensión autónoma y cooperativa de la defensa. Por último, el decreto se destaca dentro las directrices destinadas a lograr la implementación e instrumentalización de la política de defensa con el fin de realizar una gestión sistemática e inte- 
gral de los recursos de la defensa, para maximizar la eficiencia en su utilización para el logro efectivo del accionar militar conjunto. No obstante, cabe señalar que en el contexto regional se destacó la creación y consolidación del Consejo de Defensa Suramericano (CDS) de Unasur. En la actualidad la República de Argentina, a diferencia de otros Estados en Latinoamérica, presenta una clara separación entre la defensa nacional y la seguridad interior debido a los cambios en la legislación, como consecuencia de las repercusiones e impactos que ocasionaron las dictaduras cívico-militares.

En resumen, se puede decir que todas las normas y la estructura que se diseñó en materia de defensa se caracterizaron por asegurar la conducción de la política de este sector. Además, se definió la misión y los objetivos de las Fuerzas Armadas orientadas a la respuesta de agresiones militares externas, el fortalecimiento de acciones conjuntas de las tres fuerzas, a la racionalidad y la eficacia en las adquisiciones. Por otra parte, se diseñó un instrumento militar caracterizado por: integralidad, con funciones unificadas y actividades no exclusivas de las Fuerzas; con movilidad táctica y estratégica; con un despliegue de fuerzas dependiente de un único comando operacional para la paz y la guerra; con una actitud estratégica defensiva que cuenta con la capacidad para movilizar, trasladar y sostener autónomamente medios militares para contribuir a la seguridad internacional (Ugarte, 2017; Serrano Álvarez, 2018).

\subsection{Protagonistas y procesos claves en la elaboración de los documentos}

Teniendo en cuenta la evolución tanto de la estrategia como del contexto de políticas en materia de seguridad y defensa nacionales, estos antecedentes convergieron para sentar las bases en la elaboración del Libro Blanco de Defensa (Ver: Dufort, 2017). En ese orden de ideas, a comienzos de 1999 se presentó el primer documento oficial y público en el que se plantearon los principales parámetros institucionales del sistema de defensa nacional de Argentina. Esto significó el reconocimiento gubernamental y permitió la difusión pública de los lineamientos que fueron formulados a partir de la instauración de la democracia en el país.

La elaboración del Libro Blanco de 1999 estuvo a cargo del ministro de Defensa; los estudios preliminares se iniciaron en 1996 y se intensificaron luego de la II Conferencia de Ministros de Defensa de las Américas, la cual culminó con un documento por parte de un conjunto de funcionarios de aquella cartera. En su desarrollo intervinieron, entre otros, numerosos representantes de diversos 
organismos e instituciones del Gobierno nacional como la Cancillería, las propias Fuerzas Armadas, miembros y asesores de las comisiones de trabajo del Congreso Nacional. De igual forma, se unieron múltiples centros de estudio estratégicos, de relaciones internacionales y de pensamiento, fundaciones y universidades, que elaboraron las tareas preparatorias necesarias para ofrecer diferentes aportes, tanto académicos como institucionales, relacionados con aspectos de defensa nacional y sobre las relaciones cívico-militares.

Durante el año de 1996, bajo la coordinación del Estado Mayor Conjunto, cada una de las fuerzas realizó estudios que buscaban racionalizar y reformar sus estructuras organizativas y funcionales. Otro de los antecedentes de relevancia fueron las audiencias públicas desarrolladas desde agosto de 1995 en el Senado, con el objeto de analizar y debatir la reestructuración del sistema de defensa y de las Fuerzas Armadas, donde participaron varios académicos, militares, especialistas, funcionarios e incluso extranjeros. Si bien sus aportes no formaron parte fundamental del proceso de reforma institucional, sí determinaron la necesidad de que Argentina contara con un libro de defensa nacional en el que se establecieran los consensos institucionales, civiles y políticos logrados.

El resultado del proceso de construcción de este Libro Blanco de la Defensa en el plano interno se plasmó en la construcción de las bases de las relaciones civiles-militares, no solo en la subordinación militar, sino también, en la estructuración de un sistema jurídico e institucional en materia de defensa militar que se caracteriza por ser altamente institucionalizado en el marco del ejercicio efectivo de la democracia moderna. En el plano internacional, específicamente en el ámbito subregional, se propició un nuevo clima en torno a la seguridad del área que, como se mencionaba con anterioridad, se caracterizó por un cambio en la política internacional.

Esto implicó que la Cancillería, mediante sus oficios, incentivara el establecimiento de iniciativas y lazos de intercambio, cooperación e integración en materia de defensa y seguridad. De tal modo que este documento concreta el objetivo central de la defensa nacional, se centra en la preservación de la soberanía y la integridad de la nación a través de tres acciones básicas:

(i) El establecimiento de Fuerzas Armadas con estructuras redimensionadas y eficientes y con presupuestos acordes a las posibilidades económicas de la Nación; (ii) la participación activa de la Argentina en las misiones de mantenimiento de la paz llevadas a cabo por las Naciones Unidas (ONU) y por otros organismos internacionales; y (iii) el desarrollo de medidas de fomento de la confianza mutua con los países vecinos que aseguren "la transparencia y la previsibilidad de las acciones militares junto con estrategias de cooperación para la defensa común”. (Saín, 2002, p. 10) 
En ese orden de ideas, el primer Libro Blanco de la Defensa cuenta con tres apartados dentro de los que se destaca la visión del escenario estratégico desde la perspectiva Argentina, donde se describe cómo se entiende el escenario internacional del fin de la Guerra Fría y los efectos de la globalización, y, con ello, el surgimiento de nuevos riesgos de naturaleza compleja. Lo anterior supuso un conjunto de desafíos en materia de defensa y seguridad ante las amenazas clásicas a la integridad de los Estados, los factores de riesgo como la acumulación y transporte de desechos nucleares, armas biológicas y nucleares, y fuentes de inestabilidad como las disputas extra o intra-fronteras de origen histórico, cultural o territorial.

De acuerdo con lo anterior, como rasgo particular de este Libro Blanco se puede mencionar el énfasis que hace en lo concerniente al registro de los cambios producidos en los ámbitos internacional y regional, donde sobresale una postura liberal que trata de mostrar a Argentina como un Estado democrático y estable, gracias a la consolidación de la democracia desde 1983, al desarrollo de una política exterior pacifista y a la reiterada subordinación militar al poder político civil.

Luego de un desarrollo importante en materia normativa y estructural de la política de defensa y seguridad, así como de las Fuerzas Armadas — todo ello durante el gobierno de Néstor Kirchner- se aprueba el Ciclo de Planeamiento de la Defensa Nacional y la Directiva de Política de Defensa Nacional, por parte de la presidenta Cristina Fernández de Kirchner. Se implementa entonces el modelo de planeamiento por capacidades en la política de defensa y se deja atrás el antiguo modelo del enfoque por hipótesis del conflicto.

En este escenario surge el "Libro Blanco de la Defensa: Argentina Bicentenario 2010", que constituye en sí mismo una medida de confianza y de fomento de la paz entre las naciones, que, además, pretende demostrar de manera clara las características particulares del sistema de defensa nacional. El documento describe el método de planificación del desarrollo de las Fuerzas, que, ante la ausencia de amenazas convencionales externas, cambian sus procesos de desarrollo a la planificación por capacidades.

Este cambio se fundamenta en la suposición de un ambiente incierto, donde no se visualizan amenazas claras, lo que lleva a identificar a priori adversarios o enemigos de carácter estatal, contra los cuales se ha de organizar de forma reactiva el poder militar, lo que permite evadir dilemas de seguridad. Además, señala un aspecto que va más allá de las necesidades propias de la defensa nacional, porque la inscribe en un nivel supranacional al señalar que este sistema de gestión habilita la determinación de contribuciones complementarias entre los diferentes países, de este modo obtiene sinergias de la división del trabajo y del trabajo colectivo. 
Adicionalmente, este Libro Blanco se sustenta en la planificación por capacidades, con el propósito de

Promover mayor eficacia y eficiencia a la gestión de la defensa, se optimizó la administración de recursos materiales y humanos buscando maximizar la generación y sostenimiento de las capacidades militares determinadas por el planeamiento estratégico. El objetivo de esta transformación fue articular un sistema integrado de administración que permitiera traducir las capacidades aprobadas en el planeamiento, en recursos humanos, materiales e infraestructura de una manera eficaz, eficiente y transparente. (Ministerio de Defensa de la República de Argentina, 2010, p. 7)

Este documento, del 2010, actualiza el Libro Blanco de la Defensa de 1999 y se estructura en tres partes: la primera parte desarrolla el análisis de las características geoestratégicas relevantes para la República de Argentina, desde una perspectiva global hacia una regional, y presenta las características del posicionamiento estratégico defensivo en el marco de la cooperación regional. La segunda parte caracteriza el sistema de defensa argentino desde su conformación histórica y sus estructuras normativa y organizativa. Finalmente, la tercera parte describe el proceso de transformación desde 1999.

De otro lado, el Libro Blanco de la Defensa del 2015 cuenta con algunos elementos que lo diferencian de las anteriores ediciones. En primer lugar, da cuenta de la caracterización del escenario internacional en el que se desenvuelve la política de defensa nacional, gracias al protagonismo que se gana a través de la cooperación que se da por la participación en operaciones de mantenimiento de la Paz de Naciones Unidas y por el apoyo en la dinamización del Consejo de Defensa de la Unión de Naciones Suramericanas. En segundo lugar, aborda la política de género y de derechos humanos (Ministerio de Defensa de la República de Argentina, 2015, p. 261); menciona cómo se ha realizado el proceso de la transformación en formación y capacitación de los cuadros militares y civiles; y, por último, comenta los avances realizados alrededor de la ciencia, la tecnología y la producción para la defensa, así como el nuevo impulso a fabricaciones militares y al Complejo Industrial Naval Argentino (CINAR).

En ese sentido, se puede concluir que el proceso histórico que se llevó a cabo en Argentina luego del fin de las dictaduras militares tuvo como objetivo principal el cambio estratégico en la visión de la seguridad y defensa nacional como una política de Estado que no solo buscó la subordinación de las Fuerzas Militares al poder político civil, sino que procuró también la construcción de las bases legislativas y jurídicas en relación con el tema. Así mismo, buscó la reorientación de la estrategia 
de la defensa, para ello diferenció su política interna en materia de seguridad y defensa, y transformó el papel coercitivo de las Fuerzas Armadas en el plano doméstico, por otro que definió su misión desde el ámbito regional y supranacional de la cooperación.

Así mismo, se puso de manifiesto el interés de los diferentes gobiernos por consolidar la estructura de las Fuerzas Armadas, el ciclo de planeamiento en defensa e incluso la reformulación de las capacidades propias de las fuerzas orientadas a nuevas formas de capacitación y formación. Por último, este breve contexto histórico sobre la evolución de la política de defensa en Argentina demuestra el interés del Estado por dar a conocer los avances en la materia, como una expresión fundamental del trabajo mancomunado con diferentes sectores políticos y sociales, y el consenso alcanzado a la fecha no solo en el plano interno sino en el internacional.

En cuanto a la publicación de estos entramados de la política pública de defensa que son los Libros Blancos, con ellos se pretende generar climas de confianza entre los países de una misma región, al destacar el sentido de transparencia y el compromiso con la convivencia pacífica, y al poner en conocimiento de la comunidad internacional la estrategia de seguridad y defensa nacionales, así como la organización tanto en materia de recursos humanos como de recursos destinados al funcionamiento de las Fuerzas.

En este sentido, son dos los objetivos que deben cumplir los libros blancos, por un lado, en el ámbito interno el Estado, rinden cuentas ante la sociedad sobre sus propósitos de defensa, lo que lleva implícito los objetivos, medios, destino y uso de los recursos públicos. Por otro lado, en el ámbito internacional, muestran a los demás países las estrategias de seguridad de una forma transparente — para evitar percepciones distorsionadas que puedan indicar la posibilidad del surgimiento de conflictos - y fomentan el ambiente de confianza entre los Estados.

Por otra parte, para la elaboración de los libros blancos de la defensa resulta clave contar con una política de Estado en la materia, ya que son el producto final de esta y no solo de la política del Ministerio de Defensa o de las Fuerzas Armadas, por tanto, deben ser congruentes con los objetivos de Estado, incluida la política exterior. En el mismo sentido, el tema del presupuesto dedicado al sector defensa es una parte esencial, ya que como parte fundamental del debate político interno de un país es necesario evidenciar la disponibilidad presupuestal que se destinará para los gastos de funcionamiento y operacionales. No obstante, en relación con el contexto internacional, el Estado, a través del Libro Blanco, confirma el cumplimiento de las obligaciones y compromisos que surgen no solo de las relaciones bilaterales con sus vecinos sino de las regionales y multilaterales. 
La relevancia para proveer de legitimidad suficiente a la política de defensa que se traduce en estos documentos, es la consulta con los protagonistas clave. Lo anterior quiere decir, por un lado, que la elaboración de estos libros se constituye en un proceso de consulta al más alto nivel, donde el Gobierno es la autoridad competente para el establecimiento de las orientaciones con respecto a la política, el ente encargado de articular y ensamblar de manera coherente los diferentes intereses, exigencias y presiones de todos los niveles, como los son el Ministerio de Defensa, las Fuerzas Armadas, la sociedad civil, los organismos no gubernamentales, las empresas privadas, la academia, entre otros. El Gobierno tiene el deber de basarse en las recomendaciones y aportes de estos entes, así como en los resultados de las asesorías y los debates de las comisiones parlamentarias, las opiniones del público en general, de los grupos de estudio, las escuelas de pensamiento, entidades académicas y de los asociados internacionales.

En el ámbito gubernamental, son varias las entidades que deben participar en la elaboración del Libro Blanco de la Defensa, entre ellas, el Ministerio de Defensa cumple un papel determinante, así mismo, el Ministerio de Relaciones Exteriores, que es consultado a lo largo del proceso de elaboración, ya que los objetivos nacionales deben ser acordes en todo momento con la política exterior del país. De igual forma, son indispensables las consultas realizadas a los entes encargados del presupuesto y de los gastos nacionales, para definir todas las posibles restricciones de recursos para la implementación de la defensa.

De acuerdo con Borges y Banti, también deben tenerse en cuenta los temas que preocupan a los asociados internacionales interesados en el Libro Blanco, o que puedan verse afectados por el mismo. Además, se debe consultar a aquellos Estados con los que se mantengan tratados o acuerdos bilaterales o regionales (Ministerio de Defensa de la República de Argentina, 2010, p. 12), por ello, los procesos para la elaboración de los libros blancos pueden tardar varios años, tiempo en el cual no solo se debe generar todo el entramado jurídico y normativo relacionado con la política de defensa, sino también las dinámicas necesarias que permitan a los diferentes actores presentar las recomendaciones necesarias y llegar a consensos para que el producto final cuente con la aprobación y aceptación general. 


\section{Política y doctrina de defensa}

\subsection{Evaluación del entorno de seguridad y del contexto interno}

En las nuevas dinámicas y concepciones en torno a la seguridad y la defensa nacional, Argentina ha desarrollado a nivel regional un contexto de integración desde las décadas de los ochenta y los noventa en donde la dinamización comercial, específicamente de los países que conforman el Cono Sur, ha estado marcada por los diferentes acuerdos económicos bilaterales como, por ejemplo, el Mercosur, dichos esfuerzos multilaterales entre las naciones han implicado un cambio en la perspectiva internacional caracterizada, principalmente, por desarrollarse en un marco político-institucional relativamente estable, que se percibe como carente de incertidumbres, controversias o conflictos que puedan generar situaciones de inestabilidad política o imprevisibilidad jurídica entre los países (Saín, 2002, p. 126).

Lo anterior evidencia el cambio y la ruptura en la dinámica que caracterizaba el entendimiento de la defensa y la seguridad, en donde la mayoría de los países, incluido Argentina, concebían las amenazas tradicionales como aquellas relacionadas con las controversias territoriales entre dos países, las agresiones militares externas, así como la presencia dentro del territorio de organizaciones subversivas armadas de carácter comunista, maoísta o leninista, entre otras. (Ver: Álvarez Calderón, \& Rodríguez Beltrán, 2018).

Sin embargo, con los nuevos cambios en la estrategia y la comprensión de las más recientes coyunturas internacionales después de la Guerra Fría, el fin de la teoría del realismo en las relaciones internacionales y el comienzo del fenómeno de la globalización, y, con ello, de la interdependencia, emerge una serie de amenazas distintas y de orígenes diferentes que, de acuerdo con Saín, se denominan "nuevas amenazas", que corresponden a un

conjunto de riesgos y situaciones conflictivas no tradicionales, esto es, no generado por los conflictos interestatales derivados de diferendos limítrofes-territoriales o de competencias por el dominio estratégico, y que estaban particularmente sujetos a resolución de carácter militar a través del empleo o de la amenaza de empleo de las Fuerzas Armadas de los países contendientes. Estas "nuevas amenazas" han supuesto un corolario de cuestiones y asuntos que conformaron la denominada "nueva agenda de seguridad", en la que despunta el narcotráfico, el fenómeno guerrillero, el terrorismo, los conflictos étnicos, raciales, nacionalistas o religiosos, etc., es decir, amenazas de carácter interno o cuestiones que, conforme el marco institucional argentino, constituyen problemáticas claramente inscritas en el ámbito de la seguridad interior. (septiembre, 2001, p. 1) 
Por su parte, en el Libro Blanco de la Defensa de 1999, como principal exponente de la política pública de defensa, considera que respecto a las nuevas amenazas

existen nuevas manifestaciones de conflictos y peligros, de raíz histórica o emergente, bajo la forma del narcotráfico, el terrorismo, los fundamentalismos, la proliferación de armas de destrucción masiva y de sus vectores de lanzamiento, la transferencia de armamentos excedentes y tecnologías intangibles, el crimen organizado, el contrabando de armas, e incluso, el deterioro del medio ambiente y las migraciones, por falta de espacios aptos para la subsistencia, entre otros. Debido a la interdependencia, estos sucesos adquieren carácter transnacional, siendo percibidos por los Estados como cuestiones que hacen a su Seguridad y sus Intereses. (Ministerio de Defensa de la República de Argentina, 1999, p. 17)

En este sentido, es necesario mencionar que dicha conceptualización tuvo origen en la Ley N. ${ }^{\circ} 23.554$, que establece las bases jurídicas fundamentales para la ejecución y control de la defensa nacional, definida esta última como "la integración y la acción coordinada de todas las fuerzas de la Nación para la solución de aquellos conflictos que requieran el empleo de las Fuerzas Armadas, en forma disuasiva o efectiva para enfrentar las agresiones de origen externo" (art. 2). También entendida como

un conjunto de planes y acciones tendientes a prevenir o superar los conflictos que esas agresiones generen, tanto en tiempo de paz como de guerra, conducir todos los aspectos de la vida de la Nación durante el hecho bélico, así como consolidar la paz, concluida la contienda. (Ley 23.554, Art. 3)

En este orden de ideas, queda claro en la jurisprudencia argentina que la defensa nacional es una función estatal a cargo de las Fuerzas Armadas, tendiente a garantizar la seguridad externa del país. Por otra parte, en el caso de la seguridad interior opera una competencia institucional particular regida por una ley de carácter especial. Es decir que las Fuerzas Armadas cuentan con una jurisdicción institucional y exclusiva en el cumplimiento de acciones miliares y no policiales, en función de preservar la seguridad externa del Estado.

De otro lado, los intereses del Estado, en el marco de la seguridad y la defensa, se dividen en el Libro Blanco de la Defensa 1999 entre "vitales y estratégicos". Los vitales hacen referencia a la soberanía e independencia, integridad territorial, autodeterminación y la protección de la vida y libertad de los habitantes. Por su parte, los intereses estratégicos constituyen una cuestión de elevada importancia nacional respecto de los cuales el sistema de defensa no es indiferente, estos, según la normativa, son: 
la paz y seguridad internacionales; las restricciones de armas de destrucción masiva; la integración y seguridad regionales; el crecimiento económico-social; el crecimiento científico-tecnológico; la preservación de la Nación frente a la amenaza del narcotráfico y el terrorismo internacionales; los recursos naturales, renovables y no renovables; la preservación del medio ambiente; los espacios marítimos, insulares y fluviales de interés; el espacio aéreo argentino; los pasajes interoceánicos; la preservación de vacíos geopolíticos; y, la preservación del posicionamiento argentino en el Sistema Antártico. (Ministerio de Defensa de la República de Argentina, 1999 p. 43)

Por su parte, la concepción de la política de seguridad internacional de Argentina se materializa en múltiples formas desde 1999 y se centra en el apoyo a la cooperación, la no proliferación de armas nucleares, el control de armamentos que, como se verá posteriormente, están soportados en la adhesión a normas internacionales que buscan el mantenimiento de la paz.

De igual forma, es evidente en el Libro Blanco de la Defensa del 2010 que, frente a la política exterior de seguridad, el instrumento militar (Ejército, Armada y Fuerza Aérea) es concebido como una instancia integradora de los tres ambientes operacionales y su composición, dimensión y despliegue deriva del planteamiento estratégico de defensa (Ministerio de Defensa de la República de Argentina, 2010, p. 107). En la práctica, esto limita las condiciones para su empleo efectivo, es decir, que las Fuerzas actúan bajo una misión principal y unas misiones subsidiarias.

En relación con lo anterior, el entorno de defensa gira alrededor de salvaguardas determinadas por parte del Estado frente al desarrollo de las misiones. Esto se evidencia, en primer lugar, en la participación en las operaciones multilaterales de las Naciones Unidas, que es considerada en términos estrictamente técnico-militares, es decir, con incidencia en el diseño, determinación y actualización de las capacidades del instrumento militar sin el compromiso de los recursos y capacidades mismas. En segundo lugar, la participación de las Fuerzas Armadas en la construcción de un sistema de defensa subregional apunta a la consolidación progresiva de mayores niveles de confianza para alcanzar los estándares deseados en materia de acción conjunta-combinada. En tercer lugar, las operaciones de apoyo a la comunidad nacional, o de países amigos ante situaciones de catástrofe u otras circunstancias previstas en las normas, se realizan teniendo como punto de partida las capacidades operaciones y logísticas remanentes, en otras palabras, estas no pueden interferir en el cumplimiento de la misión primordial.

De otra parte, en el Libro Blanco de la Defensa de 2015 no se percibe un importante cambio en la interpretación de los contextos internacional y continental, 
y se reivindica la importancia de la cooperación como medio de construcción de confianza entre los Estados, con el objeto de que esta contribuya al mantenimiento de la paz internacional.

Sin embargo, aparece dentro del escenario internacional un especial interés acerca de las profundas transformaciones en las formas de librar la guerra, pensar la estrategia, el arte operacional y la táctica militar, en donde el papel del ser humano empieza a diluirse frente a la llegada al teatro de operaciones de drones, robots y otro tipo de plataformas con gran poder destructivo y de proyección de fuerza. Argentina, entonces, establece que para contrarrestar los efectos de un posible ataque cibernético es necesaria una rápida adaptación de los sistemas de defensa y el desarrollo de capacidades específicas en el ámbito operacional (Ministerio de Defensa de la República de Argentina, 2015).

En el contexto de seguridad interna, Argentina se basa en la decisión prevista en la Constitución política, en la ley de seguridad interior y otras normas. Sin embargo, aunque el poder ejecutivo avanzó desde el 2006 en temas referentes a la organización y el gobierno de las Fuerzas Armadas — por medio normas, decretos y resoluciones ministeriales_- en la práctica, estas son organizadas y gobernadas en función de las decisiones del gobierno de turno, lo que las pone en situación de riesgo institucional (Organización de Estados Americanos, 2016, p. 4).

Además, en el contexto interno, surgen nuevos conflictos, diferentes amenazas - muchas de ellas con dimensiones y características diferentes-, entre estas se encuentra la comercialización de la droga y la dificultad para combatir este flagelo; el terrorismo, manifiesto en el atentado a la Embajada de Israel y al edifico de la AMIA. A esto se le suma el problema de territorio, donde las fronteras están escasamente custodiadas; el problema aéreo, ya que los controles son insuficientes para disuadir los vuelos ilegales; y el problema marítimo, porque la riqueza ictícola del mar está siendo depredada (Organización de Estados Americanos, 2016, p. 4).

En pocas palabras, en Argentina existe una clara diferencia conceptual y estratégica frente a la seguridad y la defensa nacional, es decir, una separación entre la estrategia de defensa eminentemente definida como la respuesta a amenazas externas frente a las cuales ejerce todo su rol el instrumento militar, y, por otro lado, el ámbito doméstico, en el cual ejerce su actividad principal el instrumento policial.

\subsection{Estrategia de reacción frente a peligros percibidos y de cumplimiento de compromisos internacionales}

Como se mencionaba en el apartado anterior, la nueva situación de seguridad en el Cono Sur — basada en la dinamización comercial y los diferentes acuerdos 
económicos bilaterales y de la región — permitió dar un paso a la adecuación de la estrategia de seguridad y defensa en Argentina desde la década de los noventa

De acuerdo con Saín, la firma del compromiso de Santiago en 1992, de este compromiso revitalizó la vigencia de la Organización de los Estados Americanos (OEA) en relación con la seguridad cooperativa, y desempeñó un papel predominante en la elaboración y formulación de acuerdos hemisféricos (2001, p. 25). En el marco de las reuniones convocadas por este organismo, se aprobó, por iniciativa de Argentina, un listado de medidas de carácter político y diplomático ilustrativo, así como de carácter militar — como lo fueron las relacionadas con el movimiento de tropas y ejércitos, intercambio de información militar, intercambio de personal castrense, comunicación entre autoridades militares, intercambio de experiencias, entre otras - para fomentar la confianza de los otros Estados. Además, las características actuales del escenario internacional ejercen influencia en el ámbito de la defensa también desde el área del derecho.

El Libro Blanco de la Defensa de 1999, exponente de la política de defensa de Argentina, menciona aquellos instrumentos internacionales de mayor relevancia para el Estado, a los cuales se ha adherido según los temas particulares y las actividades con las cuales se relacionan, estos son: la Organización de las Naciones Unidas, a la Organización de los Estados Americanos, el respeto del Derecho Internacional de Guerra (agrupado en el conjunto de Convenciones de la Haya), el Derecho Internacional Humanitario (Convención de Ginebra de 1948 y protocolos adicionales, así como, el papel del Comité Internacional de la Cruz Roja) (Ministerio de Defensa de la República de Argentina, 1999, p. 38).

En cuanto a armas nucleares, se adhiere al Tratado sobre la No Proliferación de Armas Nucleares (TNP) y acepta las salvaguardias del Organismo Internacional de Energía Atómica (oIEA); el Tratado para la Proscripción de las Armas Nucleares en la América Latina y el Caribe (Tlatelolco) compromete a sus miembros a utilizar la energía nuclear con fines exclusivamente pacíficos y a no permitir la introducción ni desarrollo de estas armas en la región, para ello establece mecanismos de control para el cumplimiento de estas obligaciones por parte de sus miembros (Ministerio de Defensa de la República de Argentina, 1999, p. 39).

En concordancia con lo anterior, la Comisión Nacional de Energía Atómica (CNEA) ha tenido como principal función el asesoramiento al poder ejecutivo sobre la política nuclear organizada en cuatro grandes áreas temáticas: la energía nuclear, las aplicaciones nucleares, la seguridad nuclear y ambiente, y la investigación y aplicaciones no nucleares. (Toledo, 2010, p. 24). 
Por otra parte, también existen otros acuerdos —en relación con la limitación de armamentos complementarios a los anteriores - que imponen obligaciones específicas de complimiento, en ellos: Convención sobre la Prohibición del Empleo, Almacenamiento, Producción y Transferencia de Minas Antipersonal y sobre su Destrucción, Convención sobre la Prohibición del Desarrollo, Producción, Almacenamiento y Uso de Armas Químicas y sobre su Destrucción; Convención sobre la Prohibición del Desarrollo, Producción y Almacenamiento de Armas Bacteriológicas y Tóxicas y sobre su Destrucción; Convención sobre Prohibiciones o Restricciones del Empleo de Ciertas Armas Convencionales que puedan Considerarse Excesivamente Nocivas o de Efectos Indiscriminados, y sus cuatro Protocolos anexos (fragmentos no localizables; minas y armas trampa; armas incendiarias y armas laser) (Ministerio de Defensa de la República de Argentina, 1999, p. 39).

En el marco de la no proliferación de misiles, aunque sin alcanzar la categoría de convenio internacional, se encuentra el Régimen de Control de Tecnología Misilística (MTCR), en el cual Argentina tuvo un papel predominantemente activo, a partir de la adopción de decisiones políticas de gran envergadura como lo fue en su momento la cancelación del Proyecto Cóndor, lo que permitió el acceso al mecanismo.

Adicionalmente, la Convención del Derecho del Mar generada en el marco de la ONU, ratificada mediante la Ley N. ${ }^{\circ} 24.543$, establece los criterios de ordenamiento internacional de las distintas áreas marítimas a partir del carácter de Estado ribereño, donde se destaca, además de lo relativo al mar territorial y la zona contigua, la soberanía que les otorga a los Estados sobre los recursos dentro de la Zona Económica Exclusiva (ZEE) hasta las 200 millas náuticas a partir de las líneas de base, y sobre la plataforma continental definida por la Convención. Por su parte, Argentina ha establecido sus espacios marítimos por medio de la Ley 23.968, del 14 de agosto de 1991 (Ministerio de Defensa de la República de Argentina, 1999, p. 39).

De otra parte, el Tratado Antártico, vigente desde 1961, aunque reserva el continente exclusivamente para usos pacíficos, no excluye el uso de equipo o personal militar con fines logísticos o tareas científicas. Además, está complementado por la Convención sobre la Conservación de los Recursos Vivos Antárticos y por el Protocolo sobre la Protección del Medio Ambiente, el cual prohíbe cualquier tipo de actividades económicas relacionadas con los recursos minerales por un periodo de cincuenta años a partir de su adopción en Madrid en 1991. 
En ese marco, es importante señalar que los países del Cono Sur tienen el $44 \%$ de la reserva natural de agua del planeta, el $25 \%$ de tierras agrocultivables y el $26 \%$, aproximadamente, de las reservas de hidrocarburos fósiles, entre gas y petróleo. Por ello, todos los Estados de la región deben estar alerta frente a la protección de su soberanía, entre ellos Argentina, que contempla en su Libro Blanco de la Defensa, que "cualquier agresión externa contra un país de la región en búsqueda de sus recursos afecta también los intereses estratégicos [del] país” (Ministerio de Defensa de la República de Argentina, 1999, p. 4).

Ahora, con respecto al cumplimiento de los compromisos internacionales, el proceso de reestructuración en materia de seguridad y defensa nacional, evidente en el Libro Blanco de la Defensa de 1999, materializa no solo los conceptos, sino también las estrategias y misiones futuras en el sector defensa. Con este proceso se perfecciona la acción del Estado frente a las amenazas de carácter interno y externo; así mismo se aclara la reacción que se prevé por parte del instrumento militar a dichas amenazas, al respecto, se puede decir que en materia de cumplimiento tanto de las misiones nacionales como de los compromisos internacionales, estos, hacia el año 2010, son más precisos en materia operacional.

Sumado a lo anterior, el cumplimiento de los compromisos internacionales se da en el marco de las operaciones militares de acuerdo con el Libro Blanco de la Defensa, que establece que estas "son todas aquellas actividades que implican el empleo de medios para el cumplimiento de misiones asignadas al instrumento militar" (Ministerio de Defensa de la República de Argentina, 2010, p. 149). Para el 2010, el personal militar argentino desarrolló operaciones en territorio nacional principalmente vinculadas a operaciones de defensa nacional y otras dispuestas por el poder ejecutivo, dentro de las que se destacan: apoyo logístico a la política antártica, prevención y extinción de incendios, asistencias ante desastres naturales y operaciones fuera del territorio nacional, en el marco de los acuerdos y obligaciones asumidos por el Estado para la participación en las misiones de paz de la ONU y de asistencia humanitaria y apoyo a las comunidades de países amigos.

En primer lugar, se desarrollaron operaciones de vigilancia y reconocimiento del espacio aéreo nacional a través de la Fuerza de Tarea Conjunta para el control del aeroespacio "Fortín", con este fin Argentina creó y puso en marcha el Sistema Nacional de Vigilancia y Control Aeroespacial (sINviCa), "cuyo objeto es controlar los movimientos en el espacio aéreo de jurisdicción nacional, incluidos los que provienen de terceros países o se dirigen hacia ellos, cumpliendo tareas de defensa aeroespacial y de control de tránsito aéreo" (Ministerio de Defensa de la República de Argentina, 2010, p. 150). Si bien la vigilancia del espacio aéreo se considera una 
tarea del ámbito de defensa nacional, constituye una actividad eventual de apoyo a la justicia y a las fuerzas de seguridad en acciones de búsqueda y rescate en catástrofes aéreas, así como a la detección de vuelos irregulares e ilegales. En este sentido, estas acciones han permitido la colaboración activa de Argentina frente a la prevención de la drogadicción y la lucha contra el narcotráfico. (Sain, 2018).

En segundo lugar, se dio un despliegue en zonas de defensa como la protección de cumbres presidenciales. A este respecto, el sistema de defensa argentino, a través del estado mayor conjunto, planificó y ejecutó dispositivos de defensa aeroespacial con motivo de la realización de cumbres presidenciales desde el 2005, tales como la IV Cumbre de las Américas (Mar del Plata, noviembre del 2005), XXX Cumbre del Mercosur (Córdoba, julio del 2006), XXXV Reunión del Consejo del Mercado Común del Sur (San Miguel de Tucumán, julio del 2008), Cumbre de Presidentes de Unasur del 2009 y del 2010 (Ministerio de Defensa de la República de Argentina, 2010, p. 150).

En tercer lugar, se realizaron operaciones de control del mar y patrullado marítimo, a través de dos áreas navales: Atlántica y Austral. La primera, responsable de la optimización de las funciones del control del mar y de todo lo relativo a los intereses marítimos; y la segunda, responsable de llevar a cabo tareas relacionadas con búsqueda y rescate de naves en emergencia en alta mar, control del mar y sus recursos y custodia del Canal de Beagle (Ministerio de Defensa de la República de Argentina, 2010, p. 153).

En cuarto lugar, se desarrollan operaciones de apoyo logístico a la actividad antártica, las cuales contribuyen a la política nacional a través de la garantía de la logística y el normal funcionamiento de las bases nacionales, en apoyo a la comunidad científica nacional e internacional y a la prestación de servicios y compromisos asumidos por el Estado en dicha zona. Dentro de las operaciones principales se destacan: contribución a la actividad científica por medio de vuelos de abastecimiento, relevo y redistribución de personal, cooperación con la Campaña de la Comisión Nacional del Límite Exterior de la Plataforma Continental (Copla) 2008-2009 y accionar militar conjunto-combinado con Bolivia y la República del Perú en el intercambio y capacitación de personal en materia antártica (Ministerio de Defensa de la República de Argentina, 2010, p. 155).

En quinto lugar, se llevaron a cabo operaciones en el marco de misiones de paz, como misiones subsidiarias asignadas al instrumento militar, y, por tanto, como parte de la política de defensa argentina y como componente central de la política exterior. En tal sentido, es importante mencionar que las Fuerzas Armadas han participado desde 1985 en misiones de paz de las Naciones Unidas, dentro de 
las que se destacan la misión de estabilización en Haití, desde 1993; Fuerza de las Naciones Unidas para el mantenimiento de la Paz en Chipre, desde 1993; Misión de las Naciones Unidas para el Referéndum del Sahara Occidental; Entrenamiento y capacitación para la paz con la contribución del Centro Argentino de Entrenamiento Conjunto para Operaciones de Paz (caecopaz), desde 1995; Plan de acción para la Implementación de la Perspectiva de Género en el Marco de las Operaciones de Paz, desde octubre de 2008, entre otros (Ministerio de Defensa de la República de Argentina, 2010, p. 157; Fernandez-Osorio, 2017; Carrascal Jácome, Cortes Nieto $\&$ Fernandez-Osorio, 2018).

En sexto lugar se encuentran las operaciones de apoyo a la comunidad nacional o de países amigos, al igual que las misiones de paz; estas se encuentran dentro de las misiones subsidiarias del instrumento militar argentino y buscan brindar apoyo frente a catástrofes naturales y emergencias que ameriten la acción integral del Estado, así como "contribuir a la racionalidad del empleo de los recursos y a propiciar eficientes estándares de interoperabilidad conjunta, conjunta-combinada y entre distintas agencias u organismos nacionales y extranjeros" (Ministerio de Defensa de la República de Argentina, 2010, p. 163).

Algunos ejemplos de estas acciones, realizadas entre los años 2011 y 2014 en el plano nacional, son: la asistencia brindada en la provincia del Neuquén ante la actividad sísmica de los volcanes Puyehue (2001) y Copahue (2012), la prestada en ocasión de las inundaciones en las provincias de Buenos Aires y del Chubut (2014), así como numerosas operaciones de búsqueda de náufragos y evacuaciones aéreas del personal de buques pesqueros y limpieza de costas.

Por otra parte, entre las acciones que se han realizado en el ámbito internacional se encuentran: operación de salvamento de personal de la Base Carlini en la Antártida, que se llevó a cabo para auxiliar al buque pesquero Bentanazos, de la empresa Antartic Sea Fisheries de bandera chilena en el 2013; colaboración en la búsqueda del velero argentino Tunante II, desaparecido en agosto del 2014 en el Océano Atlántico frente a la costa sur de Brasil; la asistencia en traslado de brigadistas y bomberos en los incendios forestales ocurridos en proximidades de la ciudad chilena de Valparaíso (Ministerio de Defensa de la República de Argentina, 2015, p. 163).

No obstante, en el escenario de defensa y seguridad nacional, particularmente, en lo relacionado a peligros percibidos, se encuentra la creciente competencia por el acceso a recursos estratégicos como el petróleo, el gas, minerales, agua dulce y alimentos, que dinamizan no solo a Argentina, sino a la región entera, caracterizada por dotación de recursos energéticos y naturales no renovables. A lo anterior se le 
puede sumar los recursos alimenticios, así como los recientes descubrimientos de hidrocarburos en la cuenca malvinense, que agregan un elemento más a la problemática de los recursos naturales estratégicos (Jaunarena, 2016c, p. 8), lo que obliga a velar tanto por el patrimonio propio como por el compartido internacionalmente.

Debido a esa visión, la estrategia militar de reacción se orientó hacia la guerra por los recursos, lo que generó una nueva doctrina que, de hecho, el poder ejecutivo afirmó al mencionar la posibilidad de conflictos con otros Estados por la posesión de recursos naturales, al vislumbrar en el futuro próximo una disputa por el agua dulce, es decir, una amenaza para Argentina (Jaunarena, 2016c, p. 9).

Con respecto a lo anterior, se puso en marcha el Plan Ejército Argentino 2025 (PEA 2025), cuya primera medida fue el traslado del Comando del II Cuerpo desde Rosario a Curuzú Cuatiá y la previsión de mudar el Comando del V Cuerpo desde Bahía Blanca a Comodoro Rivadavia, junto con otros proyectos futuros. De este modo, la doctrina de guerra por los recursos ha sido la base de la posición estratégica defensiva que impuso el gobierno nacional como directiva militar. De igual manera, en el marco de la conferencia "Defensa y Recursos Naturales", auspiciada por el Centro de Estudios Estratégicos de Defensa (CEED), y en consenso con el Consejo de Defensa Suramericano (CDS), se dieron las bases para una estrategia defensiva, a través de recomendaciones y propuestas de alcance regional referidas a la "necesidad de estructurar un esquema regional de defensa basado en la protección de los recursos naturales suramericanos entendidos como de interés regional" (Jaunarena, 2016c, p. 9).

Los recursos naturales constituyen posiblemente la mayor fuente potencial de conflictos del futuro, como consecuencia del crecimiento de la población, el deterioro del medio ambiente, la escasez de determinados recursos indispensables para la vida humana y la industria, y los avances y exigencias de la tecnología, entre otros aspectos. Los conflictos originados por la escasez de recursos naturales no sólo pueden ser interestatales, sino que pueden darse como enfrentamientos entre sectores sociales dentro de un mismo país. La escasez de recursos naturales incluye también la de tierras productivas y aptas tanto para la vida humana como para la actividad económica. Por ello, la existencia de espacios vacíos o semivacíos en los territorios de los países que los posean constituirá importantes fuentes de conflicto. (Jaunarena, 2016a, p. 7)

Otro de los peligros para Argentina son los conflictos territoriales, ya sea por diferendos aún no resueltos o producto de intentos expansionistas, como es el caso de las Malvinas, que, de hecho, no perderá vigencia pese a la resolución pacífica de las controversias con Gran Bretaña. Así mismo, la desigualdad económica y la 
pobreza no son situaciones aisladas, están relacionadas con el narcotráfico, el crimen organizado transnacional, el tráfico ilegal de armas y los ciberataques, entre otros factores, que, combinados, juegan un papel potenciador de conflictos y desequilibrio, con todo lo que esto lleva implícito.

Como reflexión final, la defensa nacional, en tanto objeto fundacional de la Argentina y uno de los fines primeros de su existencia, debe materializarse en la acción coordinada de todos los medios del Estado para preservar la seguridad de la nación frente a los riesgos, amenazas o conflictos que afecten su supervivencia, su desarrollo y sus intereses vitales, constituyendo una responsabilidad primaria e integral del estado nacional como función de gobierno, particularmente respecto a su normativa, organización y asignación de recursos. (Jaunarena, 2016a, p. 10)

Así las cosas, como se evidencia a lo largo del presente acápite, Argentina ha tenido un desarrollo paulatino en la concepción de la defensa nacional y la seguridad interna; así mismo, ha interpretado el escenario internacional frente a la definición de las amenazas emergentes y de los compromisos internacionales. A este respecto, gracias a la jurisprudencia nacional en cumplimiento de los acuerdos y tratados de índole internacional y a la adecuación del instrumento militar, Argentina ha reorientado su estrategia de reacción frente a los peligros y amenazas, tanto tradicionales como emergentes, con el fin de poseer las capacidades necesarias y los recursos suficientes para actuar en pro de los intereses nacionales. (Ver: Iazzetta, 2019).

\subsection{Funciones y misiones de las Fuerzas Armadas}

Las Fuerzas Armadas de Argentina están integradas por el Ejército, la Armada y la Fuerza Aérea, su misión principal es la de "conjurar y repeler toda agresión militar estatal externa que ponga en riesgo la soberanía e integridad territorial, y la vida y los bienes de los habitantes" (Ministerio de Defensa de la República de Argentina, 2010, p. 9), con el fin de garantizar y proteger la soberanía, independencia y autodeterminación de la nación, la integridad territorial y la vida y libertad de los habitantes.

De esta manera las Fuerzas Armadas se encuentran doctrinarias, orgánicas, funcionales y materialmente estructuradas [con] base a su misión principal. Esta meta es el criterio ordenador del diseño de fuerzas, en tanto las misiones subsidiarias no deben afectar las capacidades requeridas para el cumplimiento de su misión primaria. (Ministerio de Defensa de la República de Argentina, 2010, p. 109)

Dentro de las misiones subsidiarias de las Fuerza Armadas se ha establecido su participación en operaciones de mantenimiento de paz bajo el mandato de 
Naciones Unidas; tomar parte en operaciones de seguridad interior; apoyar a la comunidad nacional y de países amigos; y coadyuvar en la construcción de un sistema de defensa subregional (Donadio, 2005, p. 82).

En cuanto a las misiones específicas de cada Fuerza, se estableció para el Ejército servir a la patria, con el propósito de proteger los intereses vitales de la nación, los recursos naturales, la vida, la libertad y los bienes de los ciudadanos, la independencia y la soberanía territorial, así como contribuir al sostenimiento del sistema de gobierno representativo, republicano y federal (Resdal, 2016, p. 114).

Por su parte, la Fuerza Aérea tiene como misión contribuir a la defensa nacional por medio de su acción disuasiva en el aeroespacio, con el fin de garantizar y proteger permanentemente los intereses nacionales (Resdal, 2016, p. 114). En cuanto a la Fuerza Naval, esta tiene como misión alistar, adiestrar y sostener los medios de poder naval de la nación; además, debe participar tanto en operaciones de paz como en operaciones de seguridad interior, desempeñar tareas marítimas, apoyar las actividades de la Antártida y contribuir a la preservación del medio ambiente, entre otras tareas (Resdal, 2016, p. 114).

En la actualidad, se [emplean las Fuerzas Armadas] en la custodia de los actos eleccionarios (Decreto Nacional 502/2003, Constitución de Comando General Electoral); constituyen la custodia armada del Presidente de la Nación (Decreto Nacional 236/2000, Estructura de la Casa Militar); pueden ser empleadas en actividades antisubversivas (Decreto Nacional 327/1989); son empeñadas en la lucha contra el narcotráfico (Decreto Nacional 1091/2011, Operativo Escudo Norte), sin que se respete el procedimiento que establece la Ley de Seguridad Interior, y ejercen el control de la navegación aérea (Decreto Nacional 1840/2011). También se extendió el empleo de la fuerza militar en asuntos domésticos en el marco del Plan Nacional de Abordaje Integral (Ahí) durante 2008, sin la mínima claridad jurídica en su accionar. Al amparo del Decreto 228/2016 (Emergencia de Seguridad Ciudadana) continúan participando del Operativo Escudo Norte, bajo la denominación "Operativo Fronteras", donde se establecen Reglas de Protección Aeroespacial y se habilita a las Fuerzas Armadas para el control aéreo. (Jaunarena, 2016b, p. 10)

No obstante, el rol central de las Fuerzas Armadas es asumido desde un posicionamiento estratégico defensivo que deja prever al mundo su autonomía en el ejercicio de su legítima defensa ante las agresiones o amenazas, y que desde su dimensión cooperativa proyecta a futuro la defensa de los intereses vitales y recursos estratégicos de manera colectiva (Ministerio de Defensa de la República de Argentina, 2010, p. 9). 


\subsection{Capacidades}

El Ejército para Argentina, se concibe como como el instrumento militar según tres tipos de fuerza:

1) Las Fuerzas de Respuesta Regional, compuesta por aquellas organizaciones pre-posicionadas y adaptadas al espacio geoestratégico donde normalmente serán empleadas: la montańa, el monte y la meseta patagónica. 2) Las Fuerzas de Defensa Principal, compuestas por elementos de la Fuerza preparados para ejecutar operaciones militares decisivas para la defensa o recuperación de espacios de jurisdicción.

3) Las Fuerzas de Intervención Rápida, conformadas por organizaciones con gran rapidez estratégica, operacional y táctica, con características flexibles, alto grado de preparación y disponible para ser empeñadas en los espacios de jurisdicción e interés. (Ministerio de Defensa de la República de Argentina, 2015, p. 78)

La Fuerza Aérea tiene la capacidad de control de vigilancia estratégico mediante un sistema de defensa aeroespacial, planificar en red y en tiempo real, integrar los sistemas de vigilancia y control, interoperatividad conjunta y combinada, flexibilidad de modificar el eje defensivo y la precisión en el empeño, la calidad tecnológica operativa de los medios satelitales (Ministerio de Defensa de la República de Argentina, 2015, p. 79).

La Armada se ha desenvuelto en los ámbitos operacionales marítimos, fluviales e insulares con despliegue a bases de apoyo, tanto para el soporte técnico de las unidades navales como en lo referente a la vigilancia del litoral en función de la defensa nacional; además, cuenta capacidades operativas para cumplir el rol naval. A través de la Agencia Nacional de Búsqueda y Salvamento Marítimo (SAR) cumple con la responsabilidad de salvaguardar la vida humana en el mar en el marco del Convenio SAR 1979, de Hamburgo, de la Organización Marítima Internacional (омI) (Ministerio de Defensa de la República de Argentina, 2015, p. 78).

Sin embargo, datos del poderío militar de Argentina comparado con el de Chile y el de Perú, señalan "el retroceso que tuvieron las fuerzas armadas durante los gobiernos Kirchneristas, especialmente en lo que a la aviación se refiere" (Tiempo de San Juan, 18 de noviembre de 2016). En el 2013 se hundió el destructor ARA Santísima Trinidad de la Armada como consecuencia de la falta de mantenimiento; en el caso del ejército, se evidenció que salieron a operaciones incluso sin equipo básico (González, 26 de agosto de 2015). Para el 2015, existía un problema estructural por causa del escaso presupuesto. 
En cuanto a las capacidades numéricas del recurso humano las Fuerzas Armadas de Argentina (tabla 1), estas están compuestas de la siguiente manera:

Tabla 1. Personal de las Fuerzas Armadas de Argentina a 2016

\begin{tabular}{ll}
\hline Ejercito & 48.367 \\
Fuerza Aérea & 17.957 \\
Fuerza Naval & 13.521 \\
Total de efectivos & 79.845 \\
\hline
\end{tabular}

Fuente: elaboración propia con base en datos Resdal (2016).

Según el Libro Blanco de la Defensa, "las tres fuerzas cuentan con personal militar y civil, mujeres y varones, tanto para las funciones operativas como para las administrativas" (Ministerio de Defensa de la República de Argentina, 2015, p.95; ver tambien: Sepúlveda Soto \& Rivas Pardo, 2017 y Fernandez-Osorio \& LatorreRojas, 2018).

Los lineamientos para la formación de los cuadros permanentes de las fuerzas armadas argentinas [han tenido] en cuenta los cambios en los nuevos contextos en que interactúan las naciones en el siglo XXI: la creciente valorización de los recursos naturales, del desarrollo de la ciencia y la tecnología, la relevancia estratégica global de las relaciones Sur-Sur, la globalización digital y, entre otros, también los nuevos modos en los que se desenvuelven los conflictos bélicos. En este marco se desarrollaron una serie de acciones orientadas a la construcción de capacidades institucionales para garantizar la mejora continua de la formación de ciudadanos. (Ministerio de Defensa de la República de Argentina, 2015, p. 242).

Respecto a las capacidades materiales, el Ejército está compuesto tres por elementos: 1) el comando: que dispone de materiales que facilitan la conducción del componente terrestre, de división, fuerza de despliegue rápido, y de brigadas; 2) elementos de combate: dotados de medios materiales para las diversas funciones, como son: elementos básicos de combate, con la infantería y caballería; elementos de operaciones especiales, como cazadores de montańa y de monte, buzos de ejército y fuerzas especiales, con medios especializados y de alta tecnología; elementos de apoyo de fuego de la artillería de campaña y antiaérea con medios de apoyo de fuego superficie-superficie y superficie-aire; y elementos de apoyo de combate con medios que disponen de capacidades técnico-tácticas que les permiten y facilitan la ejecución de tareas específicas; y 3) elemento de apoyo logístico de personal, material y financiero, como son: arsenales, intendencia, sanidad, veterinaria y justicia, 
entre otros, para todas las fuerzas, todo ello ejecutado con materiales que permiten el abastecimiento, mantenimiento, transporte de personal y cargas, construcciones, conservación y recuperación de la salud, entre otros (Ministerio de Defensa de la República de Argentina, 2015, p. 98). Argentina tiene claro que:

\begin{abstract}
En términos de defensa, esta no es tarea exclusiva de las fuerzas armadas de un país, sino que es una responsabilidad integral de cada gobierno y cada sociedad que se respalda en sus capacidades diplomáticas, económicas, industriales, tecnológicas, políticas y humanas, así como también en su capacidad para desarrollar sus estrategias y su voluntad para ejecutarlas y sostener su soberanía, además de sus capacidades militares. (Ministerio de Defensa de la República de Argentina, 2015, p. 86)
\end{abstract}

En ese contexto, tanto el material como las capacidades con que cuentan las Fuerzas Armadas tienen como objetivo la protección de los intereses vitales de la nación en tierra, mar y aire.

\title{
3.5 Problemas presupuestales y de recursos
}

El sector de defensa argentino ha registrado en las últimas décadas una sustantiva evolución en el plano del planeamiento de recursos, con el objetivo primordial de mejorar la calidad del gasto, con una visión de eficiencia conjunta que ha incorporado herramientas propias de la gestión basada en resultados en las distintas etapas y niveles de decisión (Vega, 2016, p. 9). Sin embargo, entre 1983 y 2003 los recursos destinados al sector fueron tan solo de un 58.7\%, (Gutiérrez, 2008., p. 175). Por ejemplo, en el año 2000 el gasto militar alcanzó apenas el 1,35\% del PBI, de hecho, "el incremento escalonado de recursos presupuestarios que había sido dispuesto en la Ley de Reestructuración de las Fuerzas Armadas de 1998 aún no había sido implementado" (Canelo, 2013, p. 143).

No obstante, el gobierno lanzó el Decreto N. ${ }^{\circ} 430$, plan de ajuste que disponía una importante reducción de las retribuciones del personal del sector público nacional, incluidas las Fuerzas Armadas; y finalmente, en diciembre de 2000, la Ley N. ${ }^{\circ}$ 25.401 de Presupuesto 2001 suspendió definitivamente la aplicación de las disposiciones de la Ley N. ${ }^{\circ}$ 24.948. (Canelo, 2013, p. 143)

En el 2006 empieza a revertirse esta situación, se implementa el sistema de planificación y control de gestión; se emprende la recuperación de la capacidad aérea al 100\% con la adquisición de aviones de transporte, enlace, helicópteros y cazabombarderos. En el 2007 se adquirieron aviones y helicópteros para la aviación naval e infantería de marina, prototipos de vehículos pesados (anfibios orugas), se recupera la capacidad submarina y se profesionaliza al ejército (Gutiérrez, 2008., p. 
175). Si se observan con atención las variaciones del presupuesto anual asignado al sector defensa durante los cinco últimos años se encuentra lo siguiente:

Tabla 2. Presupuesto anual asignado para el sector defensa argentino

\begin{tabular}{cccc}
\hline Año & $\begin{array}{c}\text { Presupuesto de defensa } \\
\text { en dólares (U\$) }\end{array}$ & $\begin{array}{c}\text { Presupuesto de } \\
\text { defensa en relación } \\
\text { al PIB }\end{array}$ & $\begin{array}{c}\text { Presupuesto de defensa en relación } \\
\text { al presupuesto del Estado }\end{array}$ \\
\hline $\mathbf{2 0 1 3}$ & 4.947 .769 .486 & $1,01 \%$ & $4,31 \%$ \\
$\mathbf{2 0 1 4}$ & 4.219 .130 .969 & $1,04 \%$ & $6,35 \%$ \\
$\mathbf{2 0 1 5}$ & 5.435 .127 .918 & $0,93 \%$ & $4,03 \%$ \\
$\mathbf{2 0 1 6}$ & 4.287 .426 .700 & $0,98 \%$ & $4,32 \%$ \\
\hline
\end{tabular}

Fuente: Elaboración propia con base en datos de la Red de Seguridad y Defensa de América Latina (2016, p. 113).

Sin embargo, aunque Argentina ha tratado de generar cambios sustantivos en el sector defensa, la situación actual de las Fuerzas Armadas es deplorable. Los escasos recursos asignados generan dificultades para su modernización y operación, los salarios del personal constituyen una debilidad y el escenario político es adverso, todo esto, entre muchos otros factores, limita e impide su equipamiento y el desarrollo de las capacidades de sus hombres (Jaunarena, 2016b, p. 8).

La situación se origina en la limitación del presupuesto de defensa a aproximadamente el 1\% del PBI, combinada con un excesivo gasto en personal derivado de una estructura de personal sobredimensionada en grados medios y altos y con escaso número de tropa — que determina la abundancia de estructuras burocráticas para su justificación-, lo que significa que un $80 \%$ del presupuesto es destinado a personal, un $15 \%$ a funcionamiento (combustible, munición, mantenimiento) y un 5\% (o menos) a material, porcentaje que obviamente no permite renovar el equipamiento. Esto, por un cuarto de siglo, explica la situación actual. Como no ha sido sustancialmente modificado, las cosas no han mejorado, ni lo harán en el futuro. (Ugarte, 2017)

Esta situación es ampliamente conocida a nivel mundial, de hecho, The Military, en su edición de 2017, examina detenidamente y hace un balance de la situación de la defensa de Argentina. Destaca la necesidad de reemplazar la gran cantidad de plataformas viejas e inoperantes que tienen las Fuerzas Armadas, debido a la falta de inversión en equipamiento y a malas prácticas de mantenimiento. La publicación incluso indica que las Fuerzas son una sombra de aquellas que fueron derrotadas por el Reino Unido en 1982 (Ugarte, 2017). 
En el mismo sentido, el Diario de defensa del Reino Unido, en un artículo publicado el 7 de septiembre de 2017, señala que el Ejército argentino "casi nunca tiene los recursos para entrenar y que los escasos equipos que posee datan de los años 70" (Allison, 2017). Anota el diario que la Fuerza Aérea "consiste en gran parte en una colección de aviones obsoletos que se remonta principalmente a la década de los setenta, que a menudo permanece en tierra debido a la pobre capacidad de servicio" (Allison, 2017); lo mismo pasa con la Fuerzas de mar. El mismo diario señala que Argentina dejó de ser una fuerza militar competente; porque el Estado no hace inversión de recursos, por tanto, carecen de equipamiento y escasas horas de capacitación del personal; es decir que dejó de ser una fuerza militar capaz y competente (Allison, 2017). Por su parte, el Institute for Defence Studies and Analyses (IDSA) ha expresado que la "negligencia por espacio de dos décadas ha significado que las Fuerzas Armadas [argentinas] estén enfrentando obsolescencia en bloque" (Ugarte, 2017).

Según lo analizado has ahora, puede decirse que la agenda política de seguridad y defensa del poder ejecutivo argentino determina, de forma directa, los resultados de las Fuerzas del Estado, los cuales han permanecido atados a prioridades de naturaleza política o económica pero no militar.

\subsection{Orientación futura: modernización de las fuerzas de defensa y adquisición de armas en gran escala}

La modernización del sector defensa en el Cono Sur ha sido uno de los retos fundamentales que han asumido los países que pasaron de sistemas autoritarios a sistemas democráticos. (Gutiérrez, 2008, p. 169).

En los gobiernos de transición, como es el caso de Argentina, estos procesos sobre modernización de las Fuerzas Armadas son necesarios para dar un nuevo rumbo a la formulación de una política en el ámbito de la defensa, que tenga como eje la conducción civil del sector y el desmantelamiento del excesivo poder militar que por décadas había tenido (Gutiérrez, 2008, p. 169).

El sistema de defensa argentino ha procurado en el último tiempo, en el marco de un denominado proceso de modernización, estructurar una arquitectura de planeamiento estratégico concebida para orientar, desde una perspectiva ordenada y conjunta, la organización, dimensionamiento y despliegue de sus Fuerzas Armadas (Armada, Ejército y Fuerza Aérea) en el corto, medio y largo plazo (Vega, 2016, p. 3).

Sin embargo, dentro de las consideraciones que ha hecho el Centro de Estudios para la Defensa, cualquier proceso de reconversión ${ }^{2}$ del sistema de defensa

2 Entendiéndose por este término: "transformar para mejorar rendimientos" y "reestructurar, modernizar, adaptando la organización o sistema a nuevas necesidades" (Jaunarena, 2017a, p. 4). 
debe iniciarse, ineludiblemente, por sus propias bases y marco normativo, dado que este data de tiempo atrás y ahora el orden ha mutado a otras exigencias, por tanto, el sistema ${ }^{3}$ no satisface eficientemente su cometido, lo que requiere la reconversión de las fuerzas basada en un proceso originado en cambios del entorno estratégico, lo que incluye escenarios políticos a nivel interno y a nivel externo, así como avances tecnológicos e innovadores (Jaunarena, 2017a, p. 1).

El actual gobierno, busca afianzar la gestión [...] con apoyo de una mayoría de sectores políticos y con el objeto de revertir situaciones de inusitado desorden en el Estado, se abre la oportunidad de dirigir esfuerzos para regularizar el marco legal, que permitan asignar responsabilidades y competencias coherentes y eficientes en el ámbito de la seguridad y la defensa nacional, a fin de enfrentar con racionalidad, legalidad y eficiencia los actuales desafíos de la nación. (Jaunarena, 2017a, p. 3)

Para lograr lo anterior, es necesario que las políticas de seguridad y defensa nacionales se basen en "cómo afectarán o atacarán y no en quién lo hará, imponiendo indagar e innovar constantemente en los ámbitos del planeamiento, con el objeto de aproximarse a un contexto estratégico cada vez más complejo e incierto" (Jaunarena, 2017a, p. 4). También en la "articulación interministerial que integre las relaciones exteriores, la defensa, la seguridad, la producción, la educación, la modernización del Estado, evitando el enfoque sectorial que posee la actual directiva de política de defensa nacional" (Jaunarena, 2017a, p. 4), entre otras.

De otra parte, la estructura de los sistemas [que no satisface], debe ser analizada en lo interno, básicamente en las relaciones entre sus componentes y su interacción. Pero también en lo externo, principalmente en el conjunto de relaciones entre los componentes del sistema y los elementos de su entorno (Jaunarena, 2017b, p. 3)

Con respecto a la situación de las Fuerzas Armadas, cabe señalar que el gobierno actual está buscando que estas adquieran competencias y desarrollen las capacidades que han perdido, por ello, el poder ejecutivo está buscando apoyo, a pesar de la crisis económica y del déficit por el que atraviesa Argentina. El Ministerio de Defensa está adquiriendo algunas pocas aeronaves para reemplazar las desgastadas, como Embraer EMB-312 Tucano, Hercules L-100, sistemas y equipos (satelitales, radares, etc.) para modernizar las aeronaves C-130, con el fin de extender su vida útil (Defensa.com, 14 de marzo de 2017).

3 Es el conjunto de diversos componentes que se encuentran interrelacionados y que se afectan mutuamente para formar una unidad. Su centro de gravedad lo constituye la relación entre sus diversos elementos. Sin embargo, se debe recordar que puede existir un conjunto de objetos, pero si no están relacionados entre sí no constituyen un sistema (Jaunarena, 2017b, p. 3). 
En este escenario, el Centro de Estudios para la Defensa Nacional ha venido proponiendo "la implementación de un presupuesto plurianual que garantice los proyectos de inversión en defensa, como pronósticos que excedan al año fiscal, para generar un círculo virtuoso en la aplicación de los recursos" (Jaunarena, 2016d, p. 6).

En el mismo sentido, Julio Hang, exgeneral del Ejército argentino y director del Instituto de Seguridad Internacional y Asuntos Estratégicos del CARI (Consejo Argentino de Relaciones Internacionales), señala que:

Es imprescindible un Plan Plurianual de adquisiciones, incorporado al presupuesto, con consenso legislativo, que tome en cuenta las previsiones de la Ley 24.948 de Reestructuración de las FFAA (Ley Jaunarena) vigente e incorpore anualmente entre un $0,3 \%$ y un $0,5 \%$ del PBI a la inversión en Defensa. (Infobae, 13 de enero de 2018)

No obstante, indica que el personal militar requiere poder reentrenar de inmediato y de manera profesional; además, a futuro, se debe adquirir nueva tecnología, robótica, misilística, cibernética, inteligencia artificial, sistemas de control de tiro, radar y comunicaciones, entre una amplia gama (Infobae, 13 de enero de 2018).

La situación exige flexibilidad estratégica, para que cada Fuerza, en el marco del Planeamiento Conjunto, se adiestre — reforzada con las adquisiciones prioritarias - en respuestas adaptadas a distintos escenarios, con una versatilidad estudiada para enfrentar amenazas cambiantes, y reconfigurando organizaciones al tiempo que se responde a la crisis. Todo esto, mientras se avanza en la obtención de otros sistemas de armas y se construye un sistema de seguridad regional que nos fortalezca y nos provea de alerta temprana (early warning). (Infobae, 13 de enero de 2018)

En ese orden de ideas, Argentina debe regular legítimamente la seguridad y la defensa como base para trazar una política de Estado, donde las políticas de seguridad nacional, de defensa y de relaciones exteriores — entre otras - sean compatibles, siempre sobre la base de un análisis del entorno estratégico que defina los riesgos y amenazas de la nación.

\subsection{Estructura militar de la defensa}

La profesión militar ha venido encaminándose progresivamente hacia cambios tecnológicos, más prácticos y flexibles, y cambios misionales y doctrinales, como la internalización de las Fuerzas bajo la modalidad de acciones combinadas; temas que son claves en la reestructuración militar, no solo de Argentina sino de todos los Estados a nivel regional. 
Sin embargo, encontrarse en medio de un campo con significativas asimetrías y caracterizado por la heterogeneidad estructural, factores que dificultan el establecimiento de un orden de interés colectivo en materia de seguridad y defensa nacionales, implica un cambio de la filosofía estratégica. Esto ha llevado a cambios en Argentina que incluyen apreciar al oponente desde el concepto de enemigo y, en materia del planeamiento estratégico, a concluir que

hay prioridades debido a las necesidades graves que no admiten demoras, como el control del espacio aéreo. Pero también lo son el control del espacio marino y el terrestre. Un primer paso para incrementar la capacidad profesional podría darse con más días de navegación para la Armada (esto significa repuestos para repotenciar los buques, puesta en servicio de todos los que se pueda, munición y electrónica); horas de vuelo para la Fuerza Aérea (lo que requiere aviones de combate y la reparación de otros); y, para el Ejército, repotenciar blindados y adquirir otros a rueda, municiones, repuestos y días de campaña, entre otras demandas. (Infobae, 13 de enero de 2018)

Consecuentemente, el presidente Macri ha ordenado una reforma de fondo en la estructura militar de Argentina. Por esta razón, se estableció, a través de la Resolución 1283 del 29 de diciembre del 2017, un grupo de trabajo con la finalidad de elaborar un instrumento legal, el cual, en el plazo perentorio de nueve meses contados a partir del 1 de marzo de 2018, deberá producir un proyecto de ley que reemplace a la que actualmente rige la actividad militar en el país y que data de 1975 (Morales, 29 de diciembre de 2017; Anzelini, 2019).

\section{Conclusiones}

La permanente intervención política de las Fuerzas Armadas de Argentina produjo varios golpes de Estado, sus gobiernos de facto mantuvieron vigentes la hipótesis de conflicto con sus países vecinos, bajo la doctrina de seguridad nacional que justificaba la represión interna y promovió una perversa cooperación regional con el resto de las dictaduras militares. El declive de esta doctrina se evidenció cuando Argentina perdió la guerra de las Malvinas en 1981. Posteriormente, esa intervención política militar impactó en el diseño de la política de defensa, así como en su sistema y en el instrumento militar, el rediseño implicó una redefinición en su misión, estructura, organización y doctrina, entre otros aspectos.

En el contexto político, la redefinición del rol de las Fuerzas Armadas empieza a cambiar tras la recuperación de la democracia, en 1983. El tema predomina en la 
agenda de la defensa y se constituye en la problemática que los sucesivos gobiernos tuvieron enfrentar por medio de la implementación de propuestas legislativas. Es por ello que en el gobierno Alfonsista se promueven leyes y decretos que establecieron dichas bases y la subordinación del poder militar al poder civil. En el periodo de Menen se estableció la Ley de Seguridad Interior y se organizó la defensa nacional. Durante el mandato de los Kirchner se reglamentó la Ley de Defensa Nacional y se puso en marcha el proceso de reconversión de las Fuerzas Armadas para asegurar su condición civil y política. Así mismo, se definen las misiones, objetivos, acciones conjuntas y unificadas; el despliegue de fuerzas para la paz, movilidad táctica, estrategia y actitud defensiva; también se implementa el modelo de planeación por capacidades y se deja de un lado el modelo del enfoque de hipótesis de conflicto; fue esta la época en que se dio una de las mayores transformaciones históricas que registre este sector.

La política de seguridad y defensa argentina ha sido la resultante de procesos de integración y reformulación de aspectos políticos, sociales y culturales, así como de nuevas concepciones de lo que se entiende por el relacionamiento cívico-militar, esto ha generado profundas repercusiones internas en la evolución de las dinámicas internacionales, regionales y locales. Los lineamientos básicos de la defensa, la organización y el funcionamiento de los sistemas defensivos e instituciones castrenses, así como los vínculos entre el poder político y la reorientación del rol de las Fuerzas Armadas, se han configurado como dimensiones centrales en la definición de seguridad.

Argentina ha tenido un desarrollo paulatino en la concepción de la defensa nacional y la seguridad interna. Ha interpretado los sucesos que se han presentado en el escenario internacional en lo relativo a la definición de las amenazas emergentes y de los compromisos internacionales — gracias a la jurisprudencia nacional en cumplimiento de los acuerdos y tratados internacionales, y a la adecuación del instrumento militar-, lo que le ha permitido reorientar su estrategia de reacción tanto frente a las amenazas y peligros tradicionales como frente a los emergentes, todo ello en pro de los intereses nacionales.

En consecuencia, puede afirmarse que el campo de seguridad y defensa argentino ha sido deficitario, dado que la modernización planteada no ha estado acompańada de lineamientos estratégicos ni de una inversión que en realidad propicie cambios y la modernización del sector, situación que las conduce, tácitamente, a ser unas Fuerzas Armadas sin capacidad ni competencia estratégico-militar. Esto, a la postre, supone una condición política integral del sector, lo cual mejoraría la política de seguridad y defensa propiamente dicha. 
En la realización de los libros blancos de la defensa (1999, 2010 y 2015) han intervenido ministros de Defensa, asesores del Congreso, organismos e instituciones del Estado, miembros de las Fuerzas Armadas, Centros de Estudios, académicos, especialistas y extranjeros, lo que ha propiciado en el plano internacional un nuevo clima en torno a seguridad y defensa nacionales, cooperación e integración. Estos documentos destacan la visión en el escenario estratégico; el surgimiento de factores de riesgos que supone un conjunto de desafíos y disputas; características claves de seguridad y defensa, planificación y desarrollo de las Fuerzas Armadas con el fin de promover mayor eficacia, gestión y optimización de los recursos humanos y materiales. Se visualizan amenazas claras, con esto, se identifican adversarios o enemigos de carácter estatal contra los que se organiza el instrumento militar para evadir dilemas de seguridad. Se brinda una caracterización del escenario internacional en el que se desenvuelve la política de defensa nacional, a partir del protagonismo que se da a través de la cooperación y la participación en operaciones de mantenimiento de la Paz de Naciones Unidas. Finalmente, abordan la política de género y derechos humanos; la transformación en la formación y capacitación de los cuadros militares y civiles; los avances realizados alrededor de la ciencia, la tecnología y la producción para la defensa, entre otros aspectos fundamentales. (Ver: Hurtado Granada, 2017; Fernandez-Osorio, Cufiño-Gutierrez, Gomez-Diaz, \& Tovar-Cabrera, 2018).

La estrategia de seguridad ha alcanzado logros cualitativos en la concepción y conducción estratégica, autónoma, defensiva y cooperativa, en particular en la modernización de los criterios políticos, técnicos y militares que orientan la organización del sistema defensivo-militar. Sin embargo, las dificultades políticas, económicas y militares por las que ha tenido que pasar la Política de Defensa y Seguridad y sus instrumentos militares, han definido una compleja realidad, a la que se suman fallas administrativas que para ser superadas requieren mejoras en la eficiencia. Por otra parte, el bajo presupuesto asignado por el ejecutivo debe aumentar, pues se necesitan mayores recursos para poner a las Fuerzas Armadas a la altura de las fuerzas de los países de la región.

Los asuntos de la defensa nacional configuran cuestiones de Estado que trascienden a los gobiernos en ejercicio y a sus funcionarios, en ese sentido, las Fuerzas Armadas de Argentina han contribuido y sido partícipes en la elaboración de los libros blancos de la defensa de una manera importante, aportando ideas que ayudan a pensar en el futuro de la soberanía desde varios de ámbitos.

Colombia debe aprender de Argentina acerca de la construcción de los libros blancos de defensa, pues no ha desarrollo ninguno, de igual manera, debe permitir la participación activa de las Fuerzas Armadas en su elaboración, dado que el cono- 
cimiento de sus integrantes es amplio, especialmente en seguridad interna, y posee personal militar capacitado en el exterior que puede guiar la defensa.

El Estado colombiano en el actual escenario regional puede proyectar, a corto plazo, un libro blanco de la defensa, con la experticia, capacidades y habilidades de sus Fuerzas Armadas, adquiridas durante el conflicto armado interno. Sus miembros son actores relevantes por su competitividad y el protagonismo con que hoy cuentan ante la región y el mundo. Su conocimiento unido al de académicos nacionales e internaciones, instituciones y organismos, puede, mediante su difusión, trasmitir con claridad y transparencia la estrategia de seguridad y defensa, pero esto requiere de voluntad política.

Comparando estos dos países suramericanos se detecta cierta similitud, pues sus territorios contienen grandes reservas naturales y activos estratégicos que merecen ser preservados para las generaciones futuras, tales reservas solamente podrán ser mantenidas a partir de la puesta en marcha de estrategias de defensa y seguridad comunes entre las naciones de la región.

Finalmente, Colombia debe documentar el libro blanco de la defensa, pues significaría dar un paso fundamental, ya que implica afrontar desafíos propios y en común, permite explicar puntos de vista, objetivos y políticas en relación con la defensa en el entorno presente y futuro. Además, proyecta información necesaria para disuadir posibles amenazas a la seguridad, sirve como instrumento fiscalizador y de control parlamentario, dado que puede realizar seguimientos, verificar cumplimientos de planes y proyectos. También es una herramienta para que todo ciudadano conozca los enfoques, orientaciones y proyecciones de la política de defensa y seguridad, además, garantiza y da confianza a tanto a la sociedad como a otros países.

\section{Referencias}

Allison, G. (2017). Argentina dejó de ser una fuerza militar competente. Recuperado de https://www. infobae.com/sociedad/2017/12/01/argentina-dejo-de-ser-una-fuerza-militar-competente/

Álvarez Calderón, C., \& Rodríguez Beltrán, C. (2018). Ecosistemas criminales. Revista Científica General José María Córdova, 16(24), 1-30. https://doi.org/10.21830/19006586.352

Anzelini, L. (2019). Entre el discurso y la acción efectiva: las contradicciones de la política de defensa de Macri. Revista Científica General José María Córdova, 17(25), 69-90. https://doi. org/10.21830/19006586.386

Canelo, P. (2013). ¿Qué hacer con las fuerzas armadas? treinta años de cuestión militar en la Argentina. En Observatorio Latinoamericano. 12, 136-148. Recuperado de http://ri.conicet.gov.ar/bitstream/handle/11336/3902/CONICET_Digital_Nro.5081_A.pdf?sequence=5

Carrascal Jácome, M., Cortes Nieto, Y. \& Fernandez-Osorio, A. (2018). (Ed.). Operaciones de mantenimiento de la paz: aproximación a un sistema nacional. Bogotá D.C.: Sello Editorial ESMIC. 
Donadio, M. (2005). Atlas Comparativo de la Defensa en América Latina (1.a ed). Buenos Aires: Red de Seguridad y Defensa de América Latina (Resdal). Recuperado de https://www.resdal.org/ atlas/atlas-libro.html

Dufort, P. (2017). La influencia de la comprensión cambiante del poder sobre la estrategia: un ensayo genealógico. Revista Científica General José María Córdova, 15(19), 29-81. https://doi. org/10.21830/19006586.83

Fernandez-Osorio, A. (2017). The Participation of Colombia in United Nations' Multidimensional Peace Operations. Journal of International Peacekeeping, 21(1-2), 83 - 124. https://doi. org/10.1163/18754112-02101003

Fernandez-Osorio, A., Cufiño-Gutierrez, F., Gomez-Diaz, C., \& Tovar-Cabrera, G. (2018). Dynamics of State modernization in Colombia: the virtuous cycle of military transformation. Democracy \& Security, https://doi.org/10.1080/17419166.2018.1517332

Fernandez-Osorio, A., \& Latorre-Rojas, J. (2018). (Ed.). La construcción del rol de la mujer militar. Bogotá D.C.: Sello Editorial ESMIC.

Gil, S. (5 de julio de 1999). Las islas Malvinas y la política exterior argentina durante los 90s: Acerca de su Fundamento Teórico y de la Concepción de una Política de Estado. Consejo Argentino para las relaciones Internacionales. Recuperado de http://www.cari.org.ar/pdf/malvinas.pdf

González, M. (26 de agosto 2015). La capacidad militar argentina a punto de desaparecer. Zona Militar. Recuperado de https://www.zona-militar.com/2015/08/26/la-capacidad-militar-argentina-a-punto-de-desaparecer/

Gutiérrez, C. (2008). Modernización del sector defensa. Un análisis comparado de los casos de Argentina, Bolivia, Chile y Perú. En I. Sepúlveda y S. Alda, La administración de la Defensa en América Latina (pp.167-202). Espańa: Centros de Estudios Estratégicos.

Hurtado Granada, M. (2017). Los límites del DIH a las armas autónomas. Revista Científica General José María Córdova, 15(20), 85-100. https://doi.org/10.21830/19006586.176

Infobae (13 de enero de 2018). Reformas imprescindibles en Defensa, un ministerio de larga crisis. Infobae Recuperado de https:/www.infobae.com/def/defensa-y-seguridad/2018/01/13/reformas-imprescindibles-en-defensa-un-ministerio-de-larga-crisis/

Iazzetta, M. (2019). Seguridad ciudadana y actividad policial comunitaria en Argentina. Estudio de caso en Rosario. Revista Científica General José María Córdova, 17(25), 93-110. https://doi. org/10.21830/19006586.387

Jaunarena, H. (2016a). Conflictos del siglo XXI. Centro de Estudios para la Defensa Nacional (CEDEF), 3(21). Buenos Aires: Universidad de Belgrano.

Jaunarena, H. (2016b). Fuerzas Armadas y Seguridad Interior. Centro de Estudios para la Defensa Nacional (CEDEF), 3 (23). Buenos Aires: Universidad de Belgrano.

Jaunarena, H. (2016c). Recursos naturales. Centro de Estudios para la Defensa Nacional (CEDEF), 3(20). Buenos Aires: Universidad de Belgrano.

Jaunarena, H. (2016d). Rumbo al futuro. Centro de Estudios para la Defensa Nacional. (CEDEF), 3(18). Buenos Aires: Universidad de Belgrano.

Jaunarena, H. (2017a). Racionalizar la Fuerza Militar - II. Centro de Estudios para la Defensa Nacional (CEDEF), 4(26). Buenos Aires: Universidad de Belgrano.

Jaunarena, H. (2017b). Sistema de Defensa. Centro de Estudios para la Defensa Nacional (CEDEF), 4(30). Buenos Aires: Universidad de Belgrano. 
Juncal, S. (2013). Seguridad y Defensa: Una visión desde los países Iberoamericanos. En G. Papuchi y P. Camps (eds.), Conceptos en Seguridad y Defensa en los paises Iberoamericanos: Desde la óptica de sus Colegios de Defensa (pp. 25-52). Uruguay: Centro de Altos Estudios Nacionales, Ministerio de Defensa Nacional.

Ley N. ${ }^{\circ}$ 23.554. Congreso de la República de Argentina, Ministerio de Justicia y Derechos Humanos, Presidencia de la Nación. (26 de abril de 1988). Recuperado de http://servicios.infoleg.gob.ar/ infolegInternet/anexos/20000-24999/20988/texact.htm

Ley N.o 23.968. Congreso de la República de Argentina, Ministerio de Justicia y Derechos Humanos, Presidencia de la Nación. (14 de agosto de 1991). Recuperado de http://servicios.infoleg.gob. ar/infolegInternet/anexos/0-4999/367/norma.htm

Ley N. ${ }^{\circ}$ 24.059. Congreso de la República de Argentina, Ministerio de Justicia y Derechos Humanos, Presidencia de la Nación. (6 de enero de 1992). Recuperado de http://servicios.infoleg.gob.ar/ infolegInternet/anexos/0-4999/458/texact.htm

Ley N.o 24.948. Congreso de la República de Argentina, Ministerio de Justicia y Derechos Humanos, Presidencia de la Nación. (3 de abril de 1998). Recuperado de http://servicios.infoleg.gob.ar/ infolegInternet/anexos/50000-54999/50229/norma.htm

Ministerio de Defensa de la República de Argentina. (1999). Libro Blanco de la República de Argentina 1999. Recuperado de https://www.oas.org/csh/spanish/documentos/libro\%20blanco\%20de\%20 defensa.doc

Ministerio de Defensa Nacional de la República de Argentina. (2010). Libro Blanco de la Defensa 2010. Recuperado de https://www.files.ethz.ch/isn/157079/Libro_Blanco_de_la_Defensa_ spanish.pdf

Ministerio de Defensa de la República de Argentina. (2015). Libro Blanco de la Defensa 2015. Recuperado de http://ceed.unasursg.org/Espanol/09-Downloads/Info-Pais/Arg/LB/Libro_ blanco_2015.pdf

Morales, F. (29 de diciembre de 2017). El Gobierno pone en marcha una profunda reforma de las Fuerzas Armadas. Infobae. Recuperado de https:/www.infobae.com/politica/2017/12/29/ el-gobierno-pone-en-marcha-una-profunda-reforma-en-las-fuerzas-armadas/

Observatorio de Políticas Públicas. (2010). El Libro Blanco de la Defensa un instrumento para el fomento de la confianza y la seguridad en América. Recuperado de https://estrategiauruguay.files. wordpress.com/2014/06/2010-libro-blanco-de-la-defensa_argentina.pdf

Organización de Estados Americanos. (2016). Sistema De Seguridad Pública En Argentina. Recuperado de http://www.oas.org/dsp/Parlamentarios/Seminario/Argentina/Seguridad_Interior_Argentina.pdf

Resdal. (2016). Atlas comparativo de la defensa en América Latina y el Caribe. Argentina. Recuperado de https://www.resdal.org/assets/atlas_2016_esp_10.pdf

Saín, M. (septiembre, 2001). Las «nuevas amenazas» y las Fuerzas Armadas en la Argentina de los '90. Ponencia preparada para la sesión Democracia, militares y nuevas amenazas: Argentina y Brasil (dem-17) del Latin American Studies Association XXIII International Congress. Washington, D. C., United States. Recuperado de http://lasa.international.pitt.edu/Lasa2001/SainMarcelo.pdf

Saín, M (2002). Los dilemas de la reforma militar en la Argentina. Recuperado de https://www.resdal. org/Archivo/d000026e.htm

Saín, M. (2018). ¿¿Militarización del control del narcotráfico en Argentina? Revista Científica General José María Córdova, 16(24), 61-82. https://doi.org/10.21830/19006586.366 
Sepúlveda Soto, D., \& Rivas Pardo, P. (2017). La mujer como sujeto de protección y de pacificación en la seguridad global: estudio del aporte teórico y conceptual del Gender Mainstreaming a las relaciones internacionales. Revista Cientifica General José María Córdova, 15(19), 123-144. https://doi.org/10.21830/19006586.75

Serrano Álvarez, J. M. (2018). El paradigma de la guerra en el siglo XX. Revista Cientifica General José María Córdova, 16(23), 23-42. https://doi.org/10.21830/19006586.305

Tiempo de San Juan (18 de noviembre de 2016). El poderío militar argentino y el de los países vecinos. Tiempo de San Juan Recuperado de https:/www.tiempodesanjuan.com/elmundo/2016/11/18/ poderio-militar-argentino-paises-vecinos-156103.html

Toledo, A. (2010). El acuerdo de cooperación regional para la promoción de la ciencia y la tecnología nucleares en América Latina y el Caribe "ARCAL" como estrategia de integración regional en América Latina, 2002-2007 (tesis de pregrado, Universidad Colegio Mayor de Nuestra Señora del Rosario, Bogotá). Recuperado de http://repository.urosario.edu.co/handle/10336/2181

Ugarte, J. (2017). Argentina, Brasil, defensa: La evolución de las doctrinas, normas y estructuras de defensa en ambos países en las últimas cuatro décadas. Revista Relaciones Internacionales, (50), 247-272.

Vega, J. (2016). Planeamiento de la Defensa en Argentina: modelo y perspectivas. España: Instituto Español de Estudios Estratégicos. Recuperado de http:/www.ieee.es/Galerias/fichero/docs_ opinion/2016/DIEEEO40-2016_PlaneamientoDefensa_Argentina_JorgeMauro.pdf 